\title{
Influence of Boride Coating on the Mechanical Properties of Heat-Resistant Cobalt Alloys at Different Temperatures
}

\author{
Alexandr Alexandrovich Afanasiev \\ Belgorod State Technological University \\ named after V.G. Shukhov \\ Russia, 304012, Belgorod, Kostukov St, 46 \\ alexaf-42@mail.ru, afanasev.aa@bstu.ru
}

\author{
Anatoliy Sergeevich Borsyakov \\ Voronezh State University \\ of Engineering Technology \\ Russia, 394036, Voronezh, Revolution Avenue \\ Borcak46@mail.ru
}

\begin{abstract}
It has been proved earlier, that boriding improves cobalt durability and that of the alloys under study during treating at room temperatures. The present paper describes the influence of diffusive boric coatings on the mechanical properties of cobalt alloys during treating at high temperatures, as well as alloying influence on the kinetic of formation and phase composition of the facial layers.
\end{abstract}

Keywords-Alloying element, boride coatings, kynematic curves, heat-resistant alloys, diffusibility, microhardness.

\section{INTRODUCTION}

One of the effective ways to enhance operational characteristics of the parts for different purposes, which are subjected to intense friction, corrosive media and high temperatures, is developing new multicomponent boride containing coatings based on cobalt alloys. Authors continue multi-year research on developing mechanisms and kinematics of diffusive boride coatings formation, construct mathematic models and optimize processes of thermo-chemical treatment $[1,2]$.

\section{METHODS AND MATERIALS}

The influence of different elements of groups 4-8 on the formation kinetics and phase composition of boride containing coatings has been investigated on specially melted cobalt alloys. Regression equations of the layer thickness dependence and its phase composition on saturation time, concentration and type of alloying component has been created; graph interpretations of these dependences are shown.

\section{RESULTS}

This part describes the results of the investigation.

Nowadays, more attention is given to creating alloys, resistible for a long time to plastic deformations at high temperatures [3]. Among heat resistant alloys cobalt alloys take important place [4] due to their high stability, good plasticity, and salt corrosion resistance.

The purpose of the first stage of the experiment was to find the way to enhance mechanical properties of cobalt alloys with electrolysis borating and study boron diffusion into binary cobalt alloys with different alloying elements.

27 cobalt alloys with different additives from IV-VIII groups (table 1) have been prepared by floating-zone method [5] in argon atmosphere. Microstructures of some studied alloys are given in fig.1. ( $\mathrm{Co}-2,10,20 \% \mathrm{Re}, \mathrm{Co}-1,3,10 \% \mathrm{Nb}$ ).

The bars were forged to necessary sizes, cut into workpieces and than undergo recrystallization annealing at temperatures $\mathrm{T}=$ $1173 \mathrm{~K}$ during 20 hours. These workpieces were treated with electrolysis borating at $\mathrm{T}=1173 \mathrm{~K}$ during 1,2 and 3 hours $[6,7]$ . X-ray structure analysis, microrentgenspectral analysis and metallographic studies [8,9] allowed determining structure and phase composition of boride coatings on all investigated coatings, and determine dependence of phase composition and diffused layer depth on the electrolysis conditions: temperature, cathodic current density and saturation time.

TABLE I. CEMICAL COMPOSITION OF COBALT BINARY ALLOYS

\begin{tabular}{|l|l|l|l|l|l|}
\hline $\begin{array}{c}\text { alloy } \\
\text { o. }\end{array}$ & composition & $\begin{array}{c}\text { al- } \\
\text { loy } \\
\text { № }\end{array}$ & composition & $\begin{array}{c}\text { alloy } \\
\text { № }\end{array}$ & $\begin{array}{c}\text { composi- } \\
\text { tion }\end{array}$ \\
\hline 1 & $\mathrm{Co}+2 \% \mathrm{Ni}$ & 10 & $\mathrm{Co}+1 \% \mathrm{Mo}$ & 19 & $\begin{array}{l}\mathrm{Co}+5 \% \\
\mathrm{Re}\end{array}$ \\
\hline 2 & $\mathrm{Co}+23 \% \mathrm{Ni}$ & 11 & $\mathrm{Co}+5 \% \mathrm{Mo}$ & 20 & $\begin{array}{l}\mathrm{Co}+10 \% \\
\mathrm{Re}\end{array}$ \\
\hline 3 & $\mathrm{Co}+65 \% \mathrm{Ni}$ & 12 & $\begin{array}{l}\mathrm{Co}+10 \% \\
\mathrm{Mo}\end{array}$ & 21 & $\begin{array}{l}\mathrm{Co}+15 \% \\
\mathrm{Re}\end{array}$ \\
\hline 4 & $\begin{array}{l}\mathrm{Co}+5 \% \\
\mathrm{Mn}\end{array}$ & 13 & $\mathrm{Co}+1 \% \mathrm{Ta}$ & 22 & $\begin{array}{l}\mathrm{Co}+20 \% \\
\mathrm{Re}\end{array}$ \\
\hline 5 & $\mathrm{Co}+10 \%$ & 14 & $\mathrm{Co}+5 \% \mathrm{Ta}$ & 23 & $\begin{array}{l}\mathrm{Co}+ \\
\mathrm{Zr}\end{array}$ \\
\hline 6 & $\mathrm{Co}+20 \%$ & 15 & $\mathrm{Co}+10 \% \mathrm{Ta}$ & 24 & $\begin{array}{l}\mathrm{Co}+3 \% \\
\mathrm{Zr}\end{array}$ \\
\hline 7 & $\mathrm{Co}+5 \% \mathrm{Cr}$ & 16 & $\mathrm{Co}+1 \% \mathrm{Nb}$ & 25 & $\begin{array}{l}\mathrm{Co}+\quad 8 \% \\
\mathrm{Zr}\end{array}$ \\
\hline 8 & $\mathrm{Co}+15 \% \mathrm{Cr}$ & 17 & $\mathrm{Co}+5 \% \mathrm{Nb}$ & 26 & $\mathrm{Co}+2 \% \mathrm{Ti}$ \\
\hline 9 & $\mathrm{Co}+25 \% \mathrm{Cr}$ & 18 & $\begin{array}{l}\mathrm{Co}+10 \% \\
\mathrm{Nb}\end{array}$ & 27 & $\mathrm{Co}+6 \% \mathrm{Ti}$ \\
\hline
\end{tabular}


a)

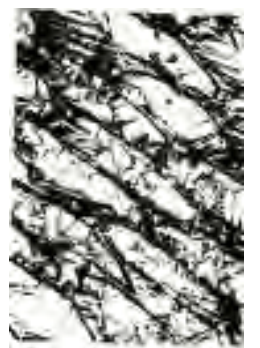

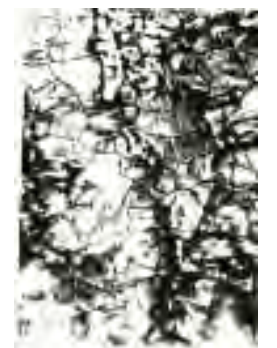

b)

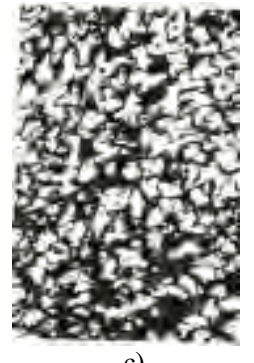

c)
Fig. 1. Microstructure of cobalt-rhenium alloys:

a) $\mathrm{Co}-2 \% \mathrm{Re}$, b) $\mathrm{Co}-10 \% \mathrm{Re}$, c) Co $-20 \%$ Re. (x 375$)$.

Fig. 2 shows dependence kinematic curves of boride layer thickness on electrolysis time for cobalt alloys with $1 \%, 3 \%$ and $8 \%$ zirconium. It is clearly seen that increasing the amount of the alloying element results in dramatic decrease of the diffusive layer thickness.

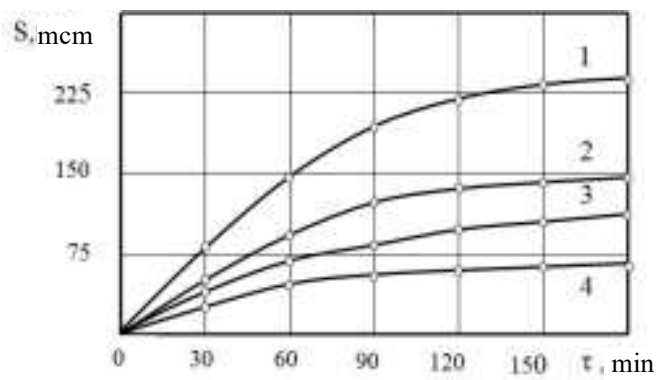

Fig. 2. Boride layer thickness dependence on electrolysis time for alloys cobalt-zirconium: $1-\mathrm{Co}, 2-\mathrm{Co}+1 \% \mathrm{Zr}, \quad 3-\mathrm{Co}+3 \% \mathrm{Zr}, \quad 4-\mathrm{Co}+8 \% \mathrm{Zr}$ $(\mathrm{T}=1173 \mathrm{~K}, \mathrm{DK}=2000 \mathrm{~A} / \mathrm{m} 2)$.

There is a dependence: $\mathrm{S} \sim \tau 1 / 2$, as well as in diffusion in the solid solution. But diffusion coefficient Deff receives in reactive diffusion effective character:

$$
\mathrm{S}_{1} \sim\left(D^{\mathrm{eff}} \tau\right)^{1 / 2}
$$

Dependence of the effective coefficient on the alloying element concentration is interesting $\mathrm{cl}$ :

$$
D_{1}{ }^{\text {eff }}=D_{0}{ }^{\text {eff }} \exp \left(\propto \frac{C_{1}}{C_{2}}\right),
$$

where D1eff and D0eff are efficiency coefficients, determining the speed of increasing boride layer in the alloy and pure cobalt; $\mathrm{c} 1$ is concentration of alloying element and $\mathrm{c} 2$ is cobalt in alloys; $\alpha$ is a coefficient depending on the nature of the alloying element.

Substituting (2) into (1), we receive:

$$
S \sim\left(D^{\mathrm{eff}} \tau\right)^{1 / 2} \exp \left(\propto \frac{\mathrm{C}_{1}}{\mathrm{C}_{2}}\right),
$$

To determine D0eff and $\alpha$ we used the method of multiplicative model calculation. The calculation was done on the computer IBM. The results are given in table 2 .

Sufficiency of every model is determined by Fisher criterion. The calculations proved that all the models in the table are 0,995 sufficient. The table shows correlation coefficients values depicting influence of electrolysis time and alloying element concentration on the layer thickness. It is shown that increase in alloying elements concentration results in decrease of layer thickness (nickel is exception)[10]

TABLE II. DEPENDENCE MATHEMATICAL MODELS OF LAYER THICKNESS ON COMPOSITION AND CONCENTRATION OF ALLOYING ELEMENTS

\begin{tabular}{|c|c|c|c|}
\hline \multirow{2}{*}{ system } & \multicolumn{2}{|c|}{$\begin{array}{c}\text { correlation co- } \\
\text { efficient }\end{array}$} & mathematical model \\
\cline { 2 - 3 } & $\boldsymbol{r}(\tau)$ & $\boldsymbol{r}(\boldsymbol{c} 1)$ & \\
\hline $\mathrm{Co}-\mathrm{Ni}$ & 0,88 & 0,36 & $\begin{array}{c}\mathrm{S}=[(15 \pm 3) \cdot 10- \\
7 \tau] 1 / 2 \exp (0,0032 \cdot \mathrm{c} 1 \mathrm{c} 2)\end{array}$ \\
\hline $\mathrm{Co}-\mathrm{Mn}$ & 0,80 & $-0,57$ & $\mathrm{~S}=[(15 \pm 3) \cdot 10-7 \tau] 1 / 2 \exp (-1,17 \cdot \mathrm{c} 1 \mathrm{c} 2)$ \\
\hline $\mathrm{Co}-\mathrm{Re}$ & 0,60 & $-0,76$ & $\mathrm{~S}=[(15 \pm 3) \cdot 10-7 \tau] 1 / 2 \exp (-3,0 \cdot \mathrm{c} 1 \mathrm{c} 2)$ \\
\hline $\mathrm{Co}-\mathrm{Mo}$ & 0,82 & $-0,51$ & $\mathrm{~S}=[(15 \pm 3) \cdot 10-7 \tau] 1 / 2 \exp (-2,94 \cdot \mathrm{c} 1 \mathrm{c} 2)$ \\
\hline $\mathrm{Co}-\mathrm{Cr}$ & 0,65 & $-0,75$ & $\mathrm{~S}=[(15 \pm 3) \cdot 10-7 \tau] 1 / 2 \exp (-1,0 \cdot \mathrm{c} 1 \mathrm{c} 2)$ \\
\hline $\mathrm{Co}-\mathrm{Ta}$ & 0,67 & $-0,72$ & $\mathrm{~S}=[(15 \pm 3) \cdot 10-7 \tau] 1 / 2 \exp (-4,8 \cdot \mathrm{c} 1 \mathrm{c} 2)$ \\
\hline $\mathrm{Co}-\mathrm{Nb}$ & 0,67 & $-0,71$ & $\mathrm{~S}=[(15 \pm 3) \cdot 10-7 \tau] 1 / 2 \exp (-4,9 \cdot \mathrm{c} 1 \mathrm{c} 2)$ \\
\hline $\mathrm{Co}-\mathrm{Ti}$ & 0,84 & $-0,52$ & $\mathrm{~S}=[(15 \pm 3) \cdot 10-7 \tau] 1 / 2 \exp (-6,4 \cdot \mathrm{c} 1 \mathrm{c} 2)$ \\
\hline $\mathrm{Co}-\mathrm{Zr}$ & 0,54 & $-0,83$ & $\mathrm{~S}=[(15 \pm 3) \cdot 10-7 \tau] 1 / 2 \exp (-11 \cdot \mathrm{c} 1 \mathrm{c} 2)$ \\
\hline
\end{tabular}

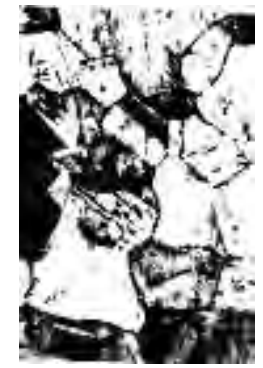

a)

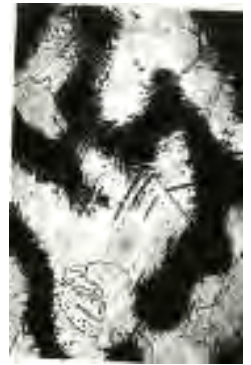

b)

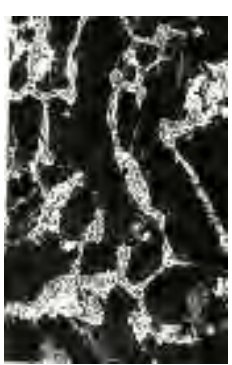

c)
Fig. 3. Niobium-cobalt alloys microstructure: a) $\mathrm{Co}-1 \% \mathrm{Nb}$, b) $\mathrm{Co}-3 \% \mathrm{Nb}$ (x 375)

Fig 4 shows dependence of logarithm of boride coating thickness on the relation of alloying element concentration to matrix. It is seen that all alloying elements decrease diffusion layer (nickel is exception). The most damping influence on boride diffusion have elements IV and V group of Mendeleev's Periodic Table, they are zirkonium, titanium, niobium, tantalic. Elements of VI and VII groups (chromium, molybdenum, rhenium and manganese) slightly decrease layer thickness, and element of VIII group nickel increases boride diffusibility in cobalt. According to damping action these alloying elements can be ranged as following: $\mathrm{Mn}, \mathrm{Cr}, \mathrm{Re}, \mathrm{Mo}, \mathrm{Ta}, \mathrm{Nb}, \mathrm{Ti}, \mathrm{Zr}$ (damping action increases from left to the right) [10].

It is known that boride with the enumerated elements forms joints of different stoichiometry. In particular, cobalt with borium produces three borides: $\mathrm{CoB}, \mathrm{Co} 2 \mathrm{~B}, \mathrm{Co} 3 \mathrm{~B}$. But analysis of boride layers on the pure cobalt showed only two phases: there is phase $\mathrm{CoB}$ on the surface with high concentration of borium and microhurdness $13500 \mathrm{Mpa}$, and the second phase, adjoining to the base, Co2B with microhardness $11000 \mathrm{Mpa}$. There were no phases Co3B in diffusive boride layer on the pure cobalt. 


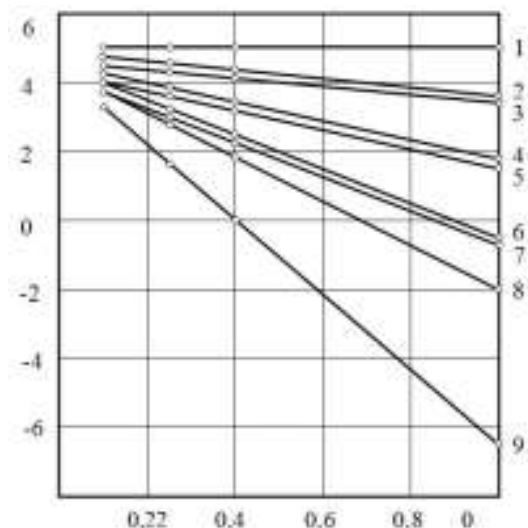

Fig. 4. Logarithmic dependence of the boride layer thickness on alloying elements concentration and matrix for further binary systems: $1-(\mathrm{Co}-\mathrm{Ni}), 2-$ (Co-Mn), 3 - (Co-Cr), 4 - (Co-Re), 5 - (Co-Mo), 6 - (Co-Ta), 7 - (Co-Nb), 8 $-(\mathrm{Co}-\mathrm{Ti}), 9-(\mathrm{Co}-\mathrm{Zr})$

Diffusive boride coatings structure on cobalt alloys after electrolyze at $1173 \mathrm{~K}$ during 90 minutes: a) $\mathrm{Co}+1 \% \mathrm{Zr}$; b) $\mathrm{Co}+3 \% \mathrm{Zr} ; \mathrm{c}) \mathrm{Co}+8 \% \mathrm{Zr} ;(\mathrm{x} 200)$

In case of cobalt alloying with elements of IV-V groups diffusive front is characterized by the presence of narrow and long boride piles, repeating the configuration of the phase reinforced with alloying element phase (Fig.5.). Boride coating hardness in this case increases significantly. As an example Fig. 6 shows graphs of microhardness changes [11] in diffusive layer for binary system $\mathrm{Co}-\mathrm{Nb}$. Introducing elements of VI-VIII group into cobalt we noticed slight coating hardness decrease $(1000-1500)$.

Coating hardness change at introducing alloying elements is explained by dissolving the latter in the layer. Actually, electron microprobe analysis showed that all studied elements dissolve very well in the layer. Their content in the coating is always less than in matrix. In case of two boride phases the presence of alloying elements in highly boride phase is less than in phase adjoining to the base.

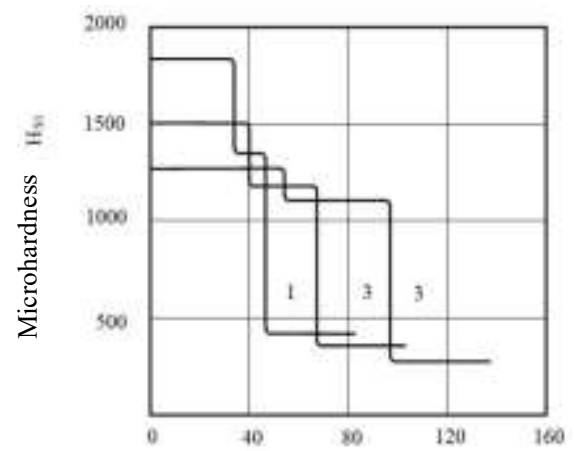

Fig. 5. Distribution of microhardness at the depth of boride layers on cobaltniobium alloys: $1-\mathrm{Co}+10 \% \mathrm{Nb}, 2-\mathrm{Co}+5 \% \mathrm{Nb}, 3-\mathrm{Co}+1 \% \mathrm{Nb}$.

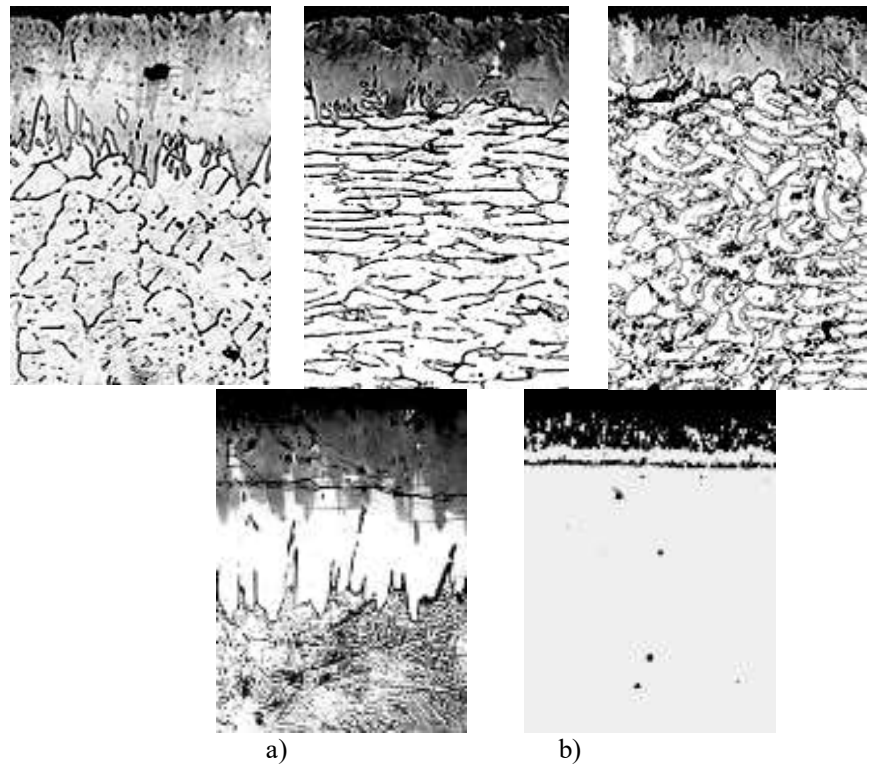

Fig. 6. Diffusive boride coatings structure on cobalt alloys after electrolysis at $1173 \mathrm{~K}$ during 120 minutes: a) $\mathrm{Co}+5 \% \mathrm{Cr}$; b) $\mathrm{Co}+25 \% \mathrm{Cr}$; ( $\mathrm{x} 200)$

For cobalt alloys with alloying elements of IV-V groups there is distinct redistribution: alloying elements are forces out the boride layer (Fig. 8,9).

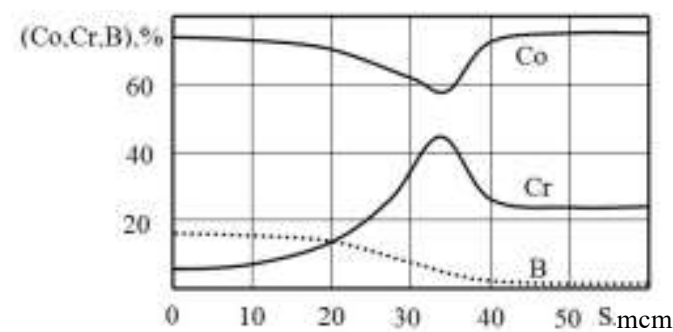

Fig. 7. Distribution of cobalt, chromium, and borium in the diffusive zone of the alloy $\mathrm{Co}+25 \% \mathrm{Cr}$ after boriding at $1173 \mathrm{~K}$ during 30 minutes.

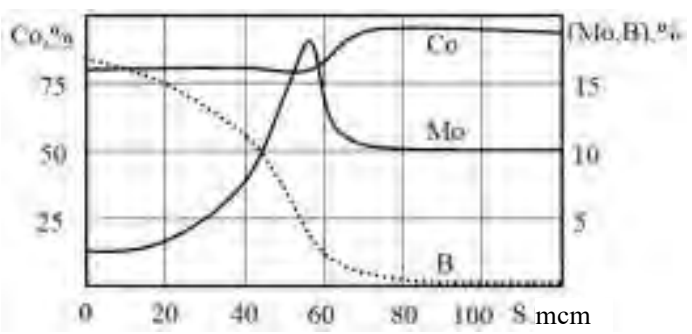

Fig. 8. Distribution of cobalt, molybdenum and borium in the diffusive zone of the alloy $\mathrm{Co}+10 \%$ Mo after electrolysis at $1173 \mathrm{~K}$ during 120 minutes.

To explain the findings we studied the dependence of the concentrated coefficient $\alpha$ on atomic radius of the alloying element. This dependence was analyzed by the method of standard deviation with a computer (Fig 10). The exponential function most closely describing is:

$$
\alpha=43,8\left(R_{2}-R_{1}\right)^{1,25}
$$

where $\mathrm{R} 2, \mathrm{R} 1$ are atomic radii of the base and alloying element respectively . 


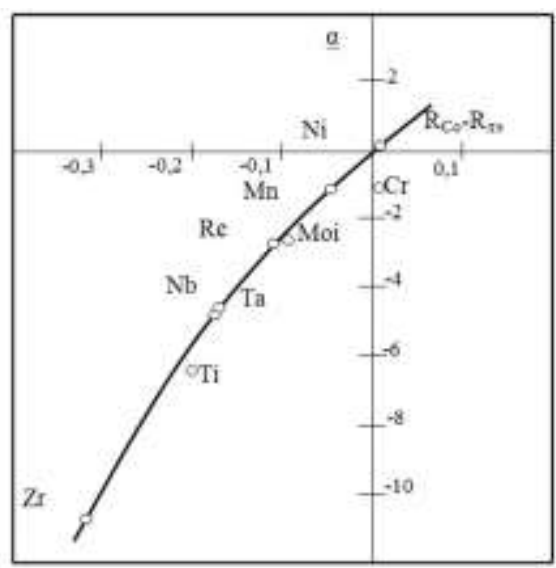

Fig. 9. Concentration coefficient $\alpha$ dependence on difference of cobalt atomic radii and alloying element.

Now, applying (4) into (3), let's find common dependence of boride layer thickness change in binary cobalt alloys:

$$
S_{1}=\left(D_{0}^{\text {эक巾 } \tau}\right)^{1 / 2} \exp \left\lfloor 43,8\left(\mathrm{R}_{2}-\mathrm{R}_{1}\right)^{1,25} \frac{c_{1}}{c^{2}}\right\rfloor
$$

As $R_{2}=1,25$ and, then

$$
S_{1}=\left(15 \pm 3 \cdot 10^{-7} \tau\right)^{1,25} \exp 43,8\left(1,25-\mathrm{R}_{1}\right)^{1,25}
$$

From the formula we can see that if the atomic radius of the alloying element is bigger than matrix atomic radius, that is the value $(\mathrm{R} 2-\mathrm{R} 1)<0$, then borium diffusion slows down. Here, cobalt is the base, if $\mathrm{c} 2>50 \%$, that is the condition should always be fulfilled $\mathrm{c} 2 / \mathrm{c} 1>1$.

Alloys heterogeneity influences significantly boride diffusion that is they consist of two and more phases. In these cases diffusion in every phase is studied separately, and taking into account their additive influence common diffusion coefficient is found or so called diffusion effective coefficient. But it is not always possible to denote diffusion parameters of in every phase. Here a reversed solution is interesting when by determining Deff we can find alloy phase condition and diffusion parameters in every phase. For this, knowing S, and the time of diffusive saturation, from formula (6) by method of least standard deviation we determined the value Deff.

The data evidence that when alloying element radius increases Deffo decreases and energy of activation increases respectively into corresponding compounding. The existing little difference in diffusion activation energy of borium into pure cobalt is explained by not precise fulfillment of exponential law. So, these investigations allow making a conclusion: the greater is the absolute value of atomic diameters difference of cobalt and alloying element, less is borium diffusibility in cobalt, the greater borium diffusion activating energy.

Heat resistant cobalt alloys have less complicated chemical and phase composition in comparison with nickel alloys. Their hardness is conditioned by solid-solution strengthening and carbide precipitation. Mostly they contain about $20 \% \mathrm{Cr}$ (surface stabilizer and carbide-forming), 10-15\% Ni (austenite stabilizer), $5-10 \% \mathrm{~W}$ (solid solution stiffener), up to $10 \%$ highmelting point metals ( $\mathrm{Ti}, \mathrm{Ta}, \mathrm{Zr}$ ). Besides, some alloys include
Mo, Si, B. In special cases alloys with $10-20 \% \mathrm{Fe}$ are applied, which resist aggressive gases below temperature 1473K. Carbon content can be up to $1 \%$ [1].

Quaternary diagrams of cobalt heat-resisting alloys show that molybdenum and tungsten increase austenite area and iron changes the form only slightly. On the whole equilibrium composition of cobalt heat resisting alloys should be viewed as in the fourth space: $\mathrm{Co} \approx 50 \%, \mathrm{Cr} \approx 20 \%$, the rest $\mathrm{Ni}, \mathrm{W}, \mathrm{Mo}$ and other metals.

That is why to solve these problems at the second stage we melted 9 cobalt alloys with constant chromium content (20\%) and changing composition $\mathrm{Ni}, \mathrm{Fe}, \mathrm{Si}, \mathrm{Mo}$ and $\mathrm{Cu}$ (TABLE 3).

We applied mathematical methods of experiment planning to study the influence of boride coatings on the mechanical properties of cobalt alloys. As key factors we chose yield values and relative elongation. The workpieces lo $=10$ do were tested. 128 workpieces were tested at different temperatures with two concurrent engineering. The investigations were done according to the full factorial experiment 24-1 with fractionary half-replicate $\mathrm{X} 4=\mathrm{x} 1 \times 2 \times 3$.

TABLE III. PLANNING MATRIX AND TRIAL RESULTS OF COBALT ALLOYS MECHANICAL PROPERTIES BEFORE AND AFTER

\begin{tabular}{|c|c|c|c|c|c|c|c|c|c|c|c|c|}
\hline \multirow[t]{2}{*}{ № } & \multicolumn{3}{|c|}{ Planning matrix } & \multicolumn{5}{|c|}{ Contents al. el., \% } & \multicolumn{4}{|c|}{ mechanical properties } \\
\hline & $x 1$ & $x 2$ & $x 3$ & $x 4$ & $\begin{array}{l}\mathrm{Ni} / \\
\mathrm{Fe}\end{array}$ & $S i$ & Mo & $\mathrm{Cu}$ & $\begin{array}{c}\sigma B, \\
M P a\end{array}$ & $\delta, \%$ & $\begin{array}{l}\sigma B 1, \\
M P a\end{array}$ & $\delta 1, \%$ \\
\hline 1 & +1 & +1 & +1 & +1 & 10 & 7 & 7 & 10 & 482 & 7,8 & 573 & 5,4 \\
\hline 2 & +1 & -1 & +1 & -1 & 10 & 1 & 7 & 0 & 520 & 23,2 & 631 & 20,1 \\
\hline 3 & -1 & +1 & +1 & -1 & 1 & 7 & 7 & 0 & 552 & 13,5 & 668 & 9,6 \\
\hline 4 & -1 & -1 & +1 & +1 & 1 & 1 & 7 & 10 & 515 & 4,8 & 608 & 4,6 \\
\hline 5 & +1 & +1 & -1 & -1 & 10 & 7 & 1 & 0 & 643 & 3,2 & 778 & 2,9 \\
\hline 6 & +1 & -1 & -1 & +1 & 10 & 1 & 1 & 10 & 442 & 3,2 & 529 & 3,0 \\
\hline 7 & -1 & +1 & -1 & +1 & 1 & 7 & 1 & 10 & 232 & 1,2 & 261 & 1,0 \\
\hline 8 & -1 & -1 & -1 & -1 & 1 & 1 & 1 & 0 & 626 & 8,8 & 766 & 7,4 \\
\hline
\end{tabular}
BORIDING (TRIAL TEMPERATURE $293^{\circ} \mathrm{C}$ )

To study the influence of electrolysis time and alloying elements content in the alloy on the diffusion layer thickness mathematical methods of experiment planning were applied. Electrolysis borating was done at $1173 \mathrm{~K}$ and cathode current density $\mathrm{D} k=2000 \mathrm{~A} / \mathrm{m}^{2}$. Diffusive boride layer thickness was determined by metal graphic analysis. The most characteristic coating structures are shown in picture. X-ray structure analysis shows their complex composition with possible formation of the following borides:

$$
(\mathrm{Co}, \mathrm{Cr}, \mathrm{Ni}, \mathrm{Fe}, \mathrm{Mo}) \mathrm{B},(\mathrm{Co}, \mathrm{Cr}, \mathrm{Fe}) \mathrm{B} \text {, }
$$$$
(\mathrm{Co}, \mathrm{Cr}, \mathrm{Ni}, \mathrm{Fe}, \mathrm{Mo})_{2} \mathrm{~B},(\mathrm{Co}, \mathrm{Cr}, \mathrm{Fe})_{2} \mathrm{~B} \text { [1]. }
$$

As the result we obtained graphic dependences of yield limit $\left(\sigma_{\mathrm{V}}, \mathrm{MPa}\right)$ and relative elongation $(\delta, \%)$ of cobalt alloys, subjected to thermal and chemo-thermal treatment (Fig. 11). 


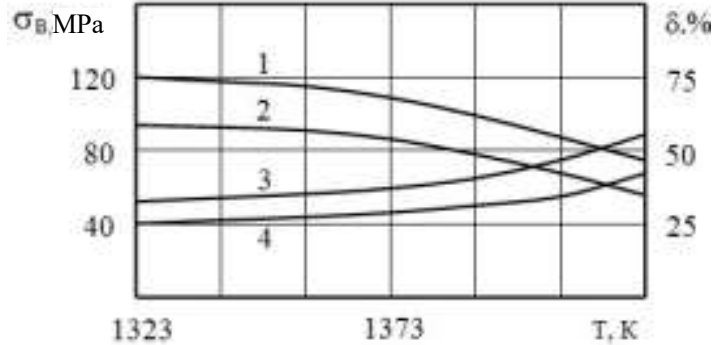

Fig. 10. Yield limit dependence (curves 1,2) and relative elongation (curves 3,4 ) on complex cobalt alloy at test temperatures: 2,3 - without boride layer, 1,4 - with boride layer $(\mathrm{T}=1173 \mathrm{~K}, \tau=120 \mathrm{~min}, \mathrm{DK}=2000 \mathrm{~A} / \mathrm{m} 2)$. Example of a figure caption.

These dependences evidence that boride coatings increase hardness of heat resistant cobalt alloys $18-25 \%$ in the whole range of temperatures.

The latter determined problem solution during the model construction with the methods of imitational model construction.

A computer experiment was conducted with the IBM: direct search method with change combinations $x_{i} \in[-1,1], i=1,4$, according to correlation (5. -7$)$ all output parameters values were calculated $\mathrm{y}_{\mathrm{j}}$. The value combination $\mathrm{x}_{\mathrm{i}}$ of the given range, when function value $y_{j}$ is maximal was the solution to the problem.

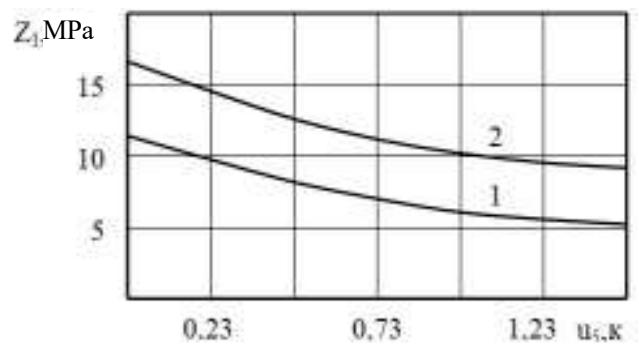

Fig. 11. Yield value difference dependence of borochromed and heat treated cobalt alloys on trial temperature: $1-u 1=10 ; u 2=2,8 ; u 3=2,8 ; u 4=4.2-u 1=10$; $\mathrm{u} 2=0,4 ; \mathrm{u} 3=2,8 ; \mathrm{u} 4=0$.

Graph interpretation of yield limit difference dependence of borochromed $\left(\mathrm{z}_{1}\right)$, and heat treated $\left(\mathrm{z}_{2}\right)$ cobalt alloys on trial temperature for different alloys is shown in Fig. 12.

\section{CONCLUSION}

1. The results of the work are shown on the graphs of yield limit dependence $\left(\sigma_{\mathrm{B}}, \mathrm{MPa}\right)$ and relative elongation $(\delta, \%)$ of cobalt alloys, after thermal and chemo-thermal treatment (Fig.11). The shown dependencies prove that boride coatings increase strength characteristics of heat resistant cobalt alloys per $18-25 \%$ in the whole range of investigated temperatures (with slight decrease in plastic properties).

2. Conducted calculations and experiments show that two-component boride coatings increase yield limit of cobalt alloys per $18-25 \%$ at room temperature and per $20-30 \%$ at high trial temperatures (1323-1423K). Alloys with boride-zirconium and lanthanum-boride coatings from 80 to $120 \mathrm{mkm}$ thickness showed maximum strength characteristics.[1].

3. It should be concluded that at treatment temperature increase from 1323 till $1423 \mathrm{~K}$ boride containing coatings influence on strength characteristics of cobalt alloys slightly decreases.

\section{Acknowledgment}

The article was prepared within development program of the Flagship Regional University on the basis of Belgorod State Technological University named after V.G. Shoukhov, using equipment of High Technology Center at BSTU named after V.G. Shoukhov

\section{REFERENCES}

[1] A.S. Borsyakov, A.A. Afanasyev, "Scientific-practical aspects of receiving multi-component borium containing coatings with high operational characteristics: Monography", Belgorod: BSTU Publishing house named after V.G. Shoukhov, 2017.

[2] A.A. Afanasiev, "Machine parts surface quality increase: Monography", Belgorod: BSTU Publishing house named after V.G. Shoukhov, 2007.

[3] A.A. Moskvitin, A.Ye. Gubanov, T.A. Duyun, "Experimental estimation of metal cutting tools properties for hard -to-machine materials treating", Bulletin of BSTU named after V.G. Shoukhov, 2017, №2, pp. 183-190.

[4] V.B. Latyshev, S.A. Moiseev, E.N. Kablov: "Heat-resistant alloy based on cobalt and tools made from it": patent. 2164959 Russian Federation. 2001.

[5] P.N. Vyugov, O.Ye. Kozhevnikov, G.Yu. Rudycheva, "Receiving highly pure hafnium samples by float zone melting", Problems of atomic science and technology, 2009, Vol. 6, № 18, pp. 19.

[6] A.A. Afanasiev, "Pecularities of electrolytic boriding and diffusive boride coatings: Strengthening technologies and coatings”, 2012, №1. pp. 3340 .

[7] M.G. Krukovich, B.A. Prusakov, N.G. Sizov, "Plasticity of borided layers", M.: PHISMATLIT, 2010.

[8] M.A. Blohin, "Methods of X-ray spectral research", M.: Phyzmatgiz, 2008

[9] S.S. Gorelic, Yu.A. Skakov, L.N. Rastorguev, "X-ray spectral research and electron - optical analysis", M.: MISA, 2007.

[10] S.G. Ivanov, M.A. Guriev, T.G. Ivanova, A.M. Guriev, "Borium diffusion research at simultaneous multi-component saturation of hydrocarbon and alloyed steels with borium, chromium and titanium", Bulletin "Innovations in machine-building": Collection of works of VII international research and practical conference, Barnaul, 2015, pp. 294 297.

[11] V.I. Moshenok, "New methods of determining metal hardness: monography", Kharkiv, KNAHU, 2012. 